\title{
Identification of Clostridium butyricum and Clostridium beijerinckii by Gas-Liquid Chromatography and Sugar Fermentation: Correlation with DNA Homologies and Electrophoretic Patterns
}

\author{
By MICHEL MAGOT, ${ }^{*}$ JEAN-PHILIPPE CARLIER AND \\ MICHEL R. POPOFF \\ Institut Pasteur - Service des Anaérobies, 28 rue du Dr Roux, 75724 Paris Cedex 15, France
}

(Received 10 December 1982; revised 6 April 1983)

\begin{abstract}
Sixty-five strains of clostridia of the butyricum group were studied by DNA-DNA hybridization, electrophoresis of cell proteins, gas-liquid chromatography, and fermentation of glycerol, inositol and ribose. The DNA-DNA hybridization results confirmed that strains of this group belong to two main species, Clostridium butyricum and C. beijerinckii. Five strains did not hybridize with the reference strains of these two species. Most of the strains could be identified by quantitative gas-liquid chromatographic analysis combined with fermentation patterns. The other strains could be identified by their protein electrophoretic patterns.
\end{abstract}

\section{INTRODUCTION}

The butyric acid-producing strains of the genus Clostridium (hereafter referred to as the butyricum group) are difficult to identify at the species level, since they are phenotypically very similar. However, Cummins \& Johnson (1971) reported that clostridia of the butyricum group fall mainly into two DNA homology groups, corresponding to two species: Clostridium butyricum (homology group I) and Clostridium beijerinckii (homology group II). These authors showed that the two species can also be differentiated by their nutritional requirements. In a recent study of $\beta$-lactamase-producing strains of the butyricum group (Magot, $1981 a, b$ ), we were unable to identify our strains using the semi-synthetic media described by Cummins \& Johnson (1971).

Electrophoretic separation of cell proteins was shown recently to be a useful technique for indentification of clostridia (Cato et al., 1982), but polyacrylamide gel electrophoresis (PAGE) is not a routine technique in anaerobe laboratories. This lack of a means of performing routine identification of clostridia of the butyricum group led us to investigate the possibility of using gas-liquid chromatography (GLC), a widely available technique in anaerobe diagnostic laboratories.

Preliminary experiments suggested that quantitative GLC might be useful in achieving complete identification of bacteria of this group, especially when GLC results are combined with the fermentation patterns of glycerol, inositol and ribose. DNA-DNA hybridization, electrophoresis of cell proteins, GLC, and fermentation patterns were used to characterize 65 strains of the butyricum group, and the results are reported in the present paper.

\section{METHODS}

Bacterial strains. The 65 strains included in this study are listed in Table 1, together with their origins and some of their characteristics. These strains were assigned to the butyricum group on the basis of the following criteria, determined according to Sebald \& Bréfort (1977); subterminal spore-forming strictly anaerobic rods; Grampositive; motile; showing no lecithinase, lipase or protease activities; fermenting fructose, glucose, lactose, maltose, mannose and sucrose with production of gas; coagulating milk; hydrolysing aesculin; and producing acetic and butyric acids as major fermentation end-products in TYG broth. These strains were non-pathogenic to mice by intraperitoneal injection. 


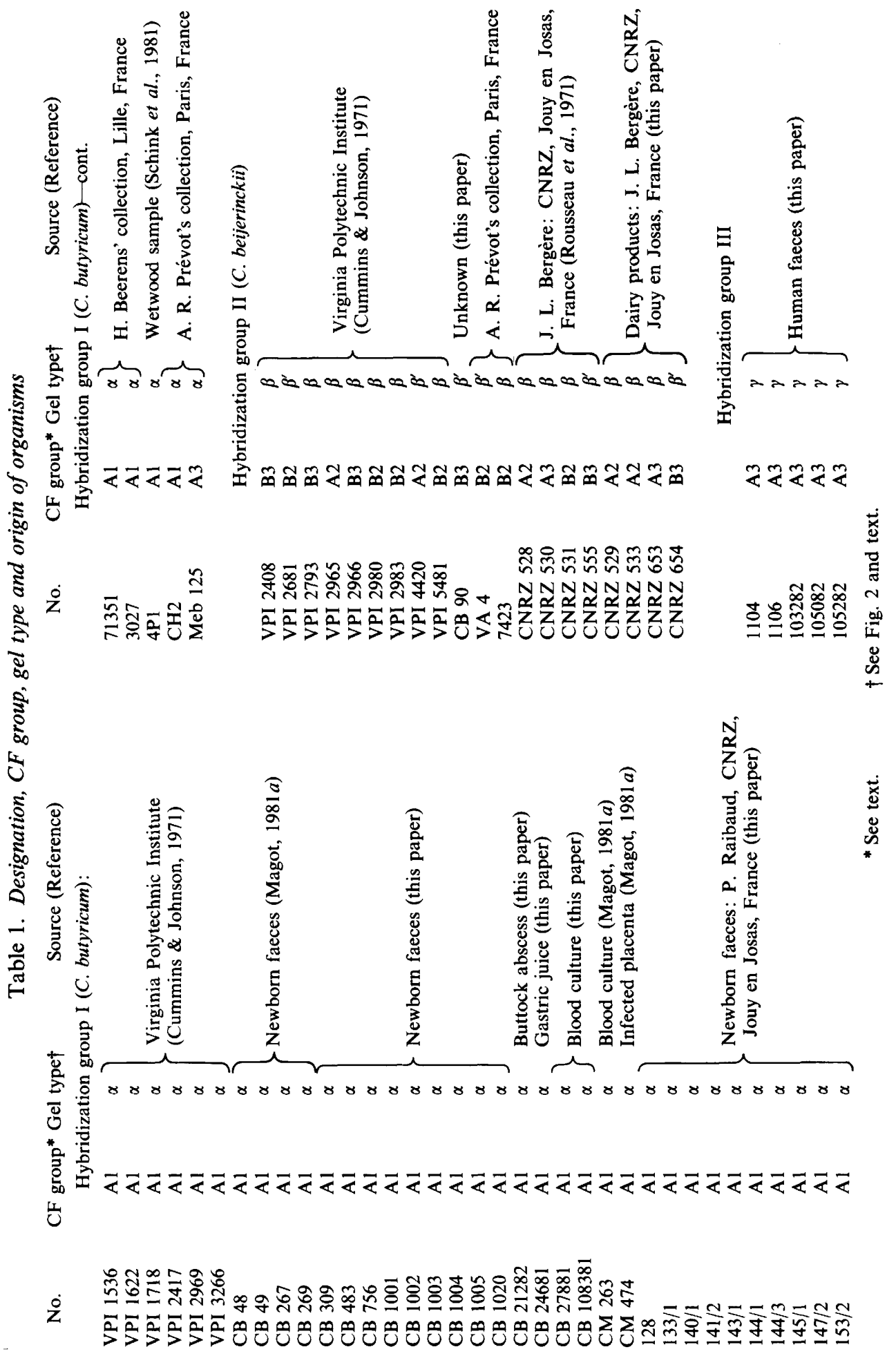


Growth. Media and methods of culture were as described by Magot (1981 $b$ ). TYG broth was supplemented with $100 \mathrm{~mm}$-sodium acetate for TYGA broth (pH 7-2). SI broth of Sebald \& Costilow (1975), where sodium thioglycolate was replaced by $0.1 \%(\mathrm{w} / \mathrm{v})$ cysteine was supplemented with $0.5 \%(\mathrm{w} / \mathrm{v})$ glucose and $100 \mathrm{mM}$-sodium acetate for SIGA broth (pH 7.0).

Sugar fermentation. Sugar fermentations were performed in TY broth $\left(\mathrm{g}^{-1}\right)$ : trypticase, 30; yeast extract, 20 ; cysteine, 1 ( $\mathrm{pH} 7 \cdot 2)$, supplemented with $1 \%(\mathrm{w} / \mathrm{v})$ carbohydrate. Inoculum was $2 \%(\mathrm{v} / \mathrm{v})$ of an overnight culture in TYG. The $\mathrm{pH}$ was measured after $18 \mathrm{~h}$ incubation at $35^{\circ} \mathrm{C}$. Fermentation was considered to be positive if a fall of $1 \mathrm{pH}$ unit or more was observed, using as control a TY broth without sugar inoculated and incubated under the same conditions.

DNA-DNA hybridization. Previously described procedures were used to extract and purify unlabelled DNAs, to shear unlabelled DNAs, and to label DNA with tritium-labelled nucleotides (Grimont et al., 1980). Labelled DNAs were from strains VPI 3266 and VPI 2983, the reference strains of $C$. butyricum and C. beijerinckii respectively (Cummins \& Johnson, 1971).

In the hybridization experiments, the $\mathbf{S 1}$ nuclease method (Crosa et al., 1973) was used. The DNA duplexes remaining after $\mathrm{Sl}$ nuclease treatment for $30 \mathrm{~min}$ at $45^{\circ} \mathrm{C}$ were separated from free nucleotides by using diethylaminoethyl-cellulose filters (DE-81 filters; Whatman) (Popoff \& Coynault, 1980). These DNA-relatedness studies were performed at $56{ }^{\circ} \mathrm{C}$ (Cummins \& Johnson, 1971). The degree of polynucleotide sequence homology was calculated by determining the ratio between the average counts in the S1-treated and untreated samples. Results, expressed as relative binding ratios (Brenner et al., 1976) were normalized to the homologous reaction after subtracting the percentage of $\mathbf{S 1 - r e s i s t a n t ~ m a t e r i a l ~ i n ~ t h e ~ c o n t r o l ~ t u b e ~ ( c o n t a i n i n g ~ o n l y ~ d e n a t u r e d ~ r a d i o a c t i v e ~}$ DNA).

$P A G E$ of cell proteins. The phenol extraction procedure for cell proteins was derived from that of Westphal \& Jann (1965). An $18 \mathrm{~h}$ culture in $30 \mathrm{ml}$ TYG broth was washed in distilled water and resuspended in Tris buffer ( $50 \mathrm{~mm}$-Tris, pH $8.0 ; 1 \mathrm{ml}$ Tris buffer for $100 \mathrm{mg}$ cells, wet weight). An equal volume of hot $\left(60^{\circ} \mathrm{C}\right)$ phenol was added and the mixture was incubated for $30 \mathrm{~min}$ at $60^{\circ} \mathrm{C}$ in a water bath, and for $30 \mathrm{~min}$ more at room temperature. After centrifugation for $20 \mathrm{~min}$ at $4500 \mathrm{~g}$, the phenol phase was extracted and then dialysed for 3 to $5 \mathrm{~d}$ against Tris buffer $/ 25 \%(\mathrm{v} / \mathrm{v})$ glycerol at $4{ }^{\circ} \mathrm{C}$. After a tenfold concentration against $10 \%(\mathrm{w} / \mathrm{v})$ polyethylene glycol 4000 in Tris buffer, the mixture was cleared by centrifugation, and one volume of a solution containing $6 \mathrm{~mm}$-Tris, $2 \%(\mathrm{w} / \mathrm{v})$ SDS, $0.004 \%$ bromophenol blue and $0.025 \% \beta$-mercaptoethanol, $\mathrm{pH} 7 \cdot 0$, was added to the supernatant. Samples were heated for $5 \mathrm{~min}$ at $100{ }^{\circ} \mathrm{C}$ in a water bath, and electrophoresed in a $0.1 \% \operatorname{SDS}$ polyacrylamide gel following the method of Laemmli (1970).

GLC. For GLC analysis, cells were grown in TYGA or SIGA broth for $3 \mathrm{~d}$ at $35^{\circ} \mathrm{C}$. After centrifugation, $80 \mu \mathrm{mol}$ isobutyric acid (internal standard), $0.4 \mathrm{ml} 50 \%(\mathrm{v} / \mathrm{v}) \mathrm{H}_{2} \mathrm{SO}_{4}$ and $4 \mathrm{ml}$ diethyl ether were added to $4 \mathrm{ml}$ of supernatant. After mixing, $1 \mu \mathrm{l}$ of the ether phase was injected into an Intersmat model IGC 131 gas chromatograph equipped with a flame-ionization detector and connected to a model ICR $1 \mathrm{~B}$ integrator. A glass column $(1.8 \mathrm{~m} \times 6 \mathrm{~mm})$ packed with $5 \%$ Resoflex LAC 1R 296 on acid-washed Chromosorb G DMCS (60-80 mesh) was used. The operating conditions were: injector temperature, $200{ }^{\circ} \mathrm{C}$; detector temperature, $250^{\circ} \mathrm{C}$; oven temperature, $125^{\circ} \mathrm{C}$; carrier gas (nitrogen) flow rate, $30 \mathrm{ml} \mathrm{min}^{-1}$; attenuation, 1 ; sensitivity, $10^{-9} \mathrm{~A}$. Typical chromatograms of $C$. butyricum VPI 3266 and $C$. beijerinckii VPI 5481 grown in SIGA broth are shown in Fig. 1.

\section{RESULTS}

\section{DNA-DNA hybridization}

Results of DNA-DNA hybridization experiments are summarized in Table 2. The S1 nuclease-resistant core (in the incubated control tubes containing only labelled DNA) was calculated to be $1.33 \pm 0.30 \%$ (mean \pm S.D). The 65 strains fell into three hybridization groups. The 40 strains of hybridization group I were 56 to $114 \%$ related to strain VPI 3266 (the reference strain of $C$. butyricum). The relative binding ratios between all other strains and strain VPI 3266 did not exceed $13 \%$. The 20 strains of hybridization group II were 58 to $92 \%$ related to strain VPI 2983 (the reference strain of $C$. beijerinckii). The relative binding ratios between all other strains and VPI 2983 did not exceed $9 \%$. None of the five strains (Clostridium spp. of the butyricum group) included in hybridization group III was more than $13 \%$ related to the reference strains of $C$. butyricum or $C$. beijerinckii.

\section{PAGE patterns}

Four PAGE patterns were obtained with phenol-extracted proteins of the butyricum group strains after SDS-PAGE (Fig. 2, Table 1). These patterns can be correlated with the DNA 

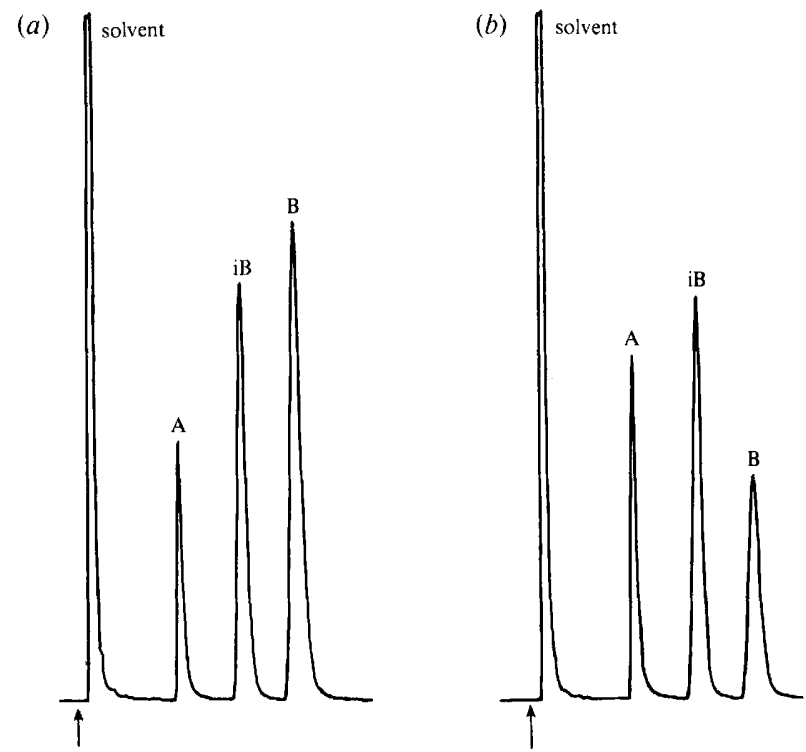

Fig. 1. Typical GLC chromatograms in SIGA broth of $(a)$ C. beijerinckii VPI 5481 and $(b)$ C. butyricum VPI 3266. A, acetic acid; iB, isobutyric acid (internal standard); B, butyric acid. The arrows indicate the injection of the sample.

Table 2. Hybridization of DNA from the 65 strains with DNAs from C. butyricum VPI 3266 and C. beijerinckii VPI 2983

Hybridization group

Group I (40 strains)

Group II (20 strains)

Group III (5 strains)
Relative binding ratio $(\%)$ with labelled DNA from:

\begin{tabular}{|c|c|c|c|}
\hline \multicolumn{2}{|c|}{ C. butyricum VPI 3266} & \multicolumn{2}{|c|}{ C. beijerinckii VPI 2983} \\
\hline Mean \pm S.D. & Range & Mean \pm S.D. & Range \\
\hline $81 \cdot 7 \pm 15 \cdot 0$ & $56 \cdot 2-114 \cdot 2$ & $5.3 \pm 1.9$ & $1 \cdot 0-8 \cdot 6$ \\
\hline $8.9 \pm 1.6$ & $6 \cdot 2-11 \cdot 2$ & $74 \cdot 2 \pm 11 \cdot 2$ & $58 \cdot 2-91 \cdot 7$ \\
\hline $9 \cdot 7 \pm 2 \cdot 7$ & $7 \cdot 0-12 \cdot 4$ & $5 \cdot 3 \pm 3 \cdot 0$ & $1 \cdot 8-8 \cdot 9$ \\
\hline
\end{tabular}

hybridization results. All strains of hybridization group I yielded a type $\alpha$ gel pattern. Types $\beta$ and $\beta^{\prime}$ patterns were obtained with strains of hybridization group II; these differed mainly by the substitution of two bands in the fastest-running area of gel type $\beta$ by a unique faint band in gel type $\beta^{\prime}$. Other differences could be seen in the middle and even in the upper parts of the gels, but in the latter case differences were not always obvious, depending on the amount of proteins loaded on the gel. Strains of hybridization group III showed a different PAGE pattern, type $\gamma$.

\section{GLC analysis of fermentation products}

In preliminary experiments, we observed that $C$. butyricum and $C$. beijerinckii strains produced different amounts of butyric acid and acetic acid as end-products of glucose fermentation. When $100 \mathrm{~mm}$-acetate was added to the growth medium, it appeared that most strains of $C$. beijerinckii produced butyric acid and metabolized small amounts of acetate, whereas most strains of $C$. butyricum produced acetate and also butyrate although in a lower amount than $C$. beijerinckii (data not shown). Taken independently, these data did not permit easy identification of all the strains tested, but differences between the two species were clearer when the butyric acid/ acetic acid ratio was determined after $3 \mathrm{~d}$ growth in a defined synthetic broth, SIGA. The results are diagrammatically shown in Fig. 3(a). All the C. butyricum strains 


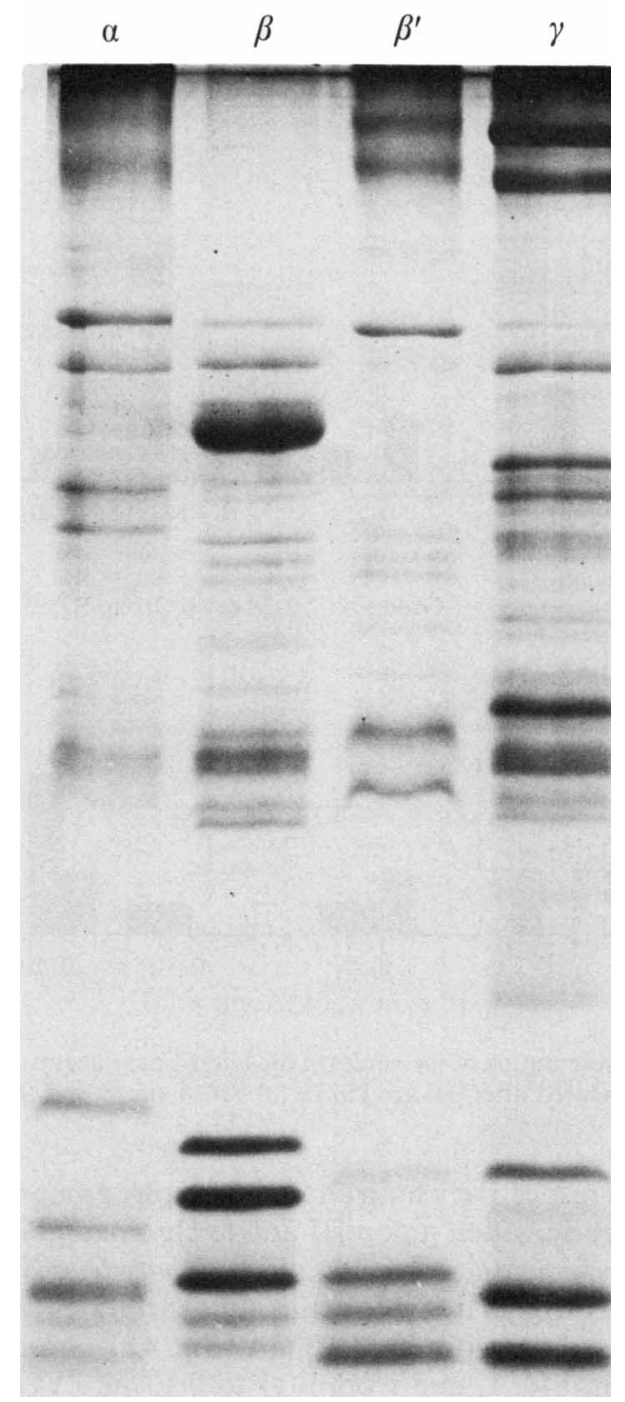

Fig. 2. PAGE patterns of cell proteins. Type $\alpha$ gels were obtained with hybridization group I strains $(C$. butyricum), type $\beta$ or $\beta^{\prime}$ with hybridization group II strains (C. beijerinckii), and type $\gamma$ with hybridization group III strains (Clostridium spp.). The stacking and resolving gels were respectively $4.7 \%$ and $12 \%$ polyacrylamide. The voltage was set at $12 \mathrm{~V} \mathrm{~cm}^{-1}$ for $4 \mathrm{~h}$. The gel was stained for $15 \mathrm{~min}$ in Coomassie blue and decolorized for several hours as described by Laemmli (1970).

had a low butyric acid/acetic acid ratio, whereas most of the $C$. beijerinckii strains had higher values $(>0 \cdot 25)$. When the same experiments were done in TYG supplemented with acetate (TYGA), similar results were obtained (Fig. $3 b$ ). From these data, we defined two 'chromatography groups': group A includes strains with a low butyric acid/acetic acid ratio $(<0.25$ in SIGA or $<0.29$ in TYGA); group B includes strains with a high butyric acid/acetic acid ratio $(\geqslant 0.25$ in SIGA or $\geqslant 0.29$ in TYGA). Figure 3 clearly shows that all strains of chromatography group B are representative of $C$. beijerinckii. Chromatography group $\mathrm{A}$ is more heterogeneous, including all the C. butyricum strains, several $C$. beijerinckii strains, and the nonhybridizing strains.

In order to test the reproducibility of this chromatographic method, 10 independent experiments after growth in SIGA and TYGA were done with $C$. butyricum VPI 3266 and $C$. 


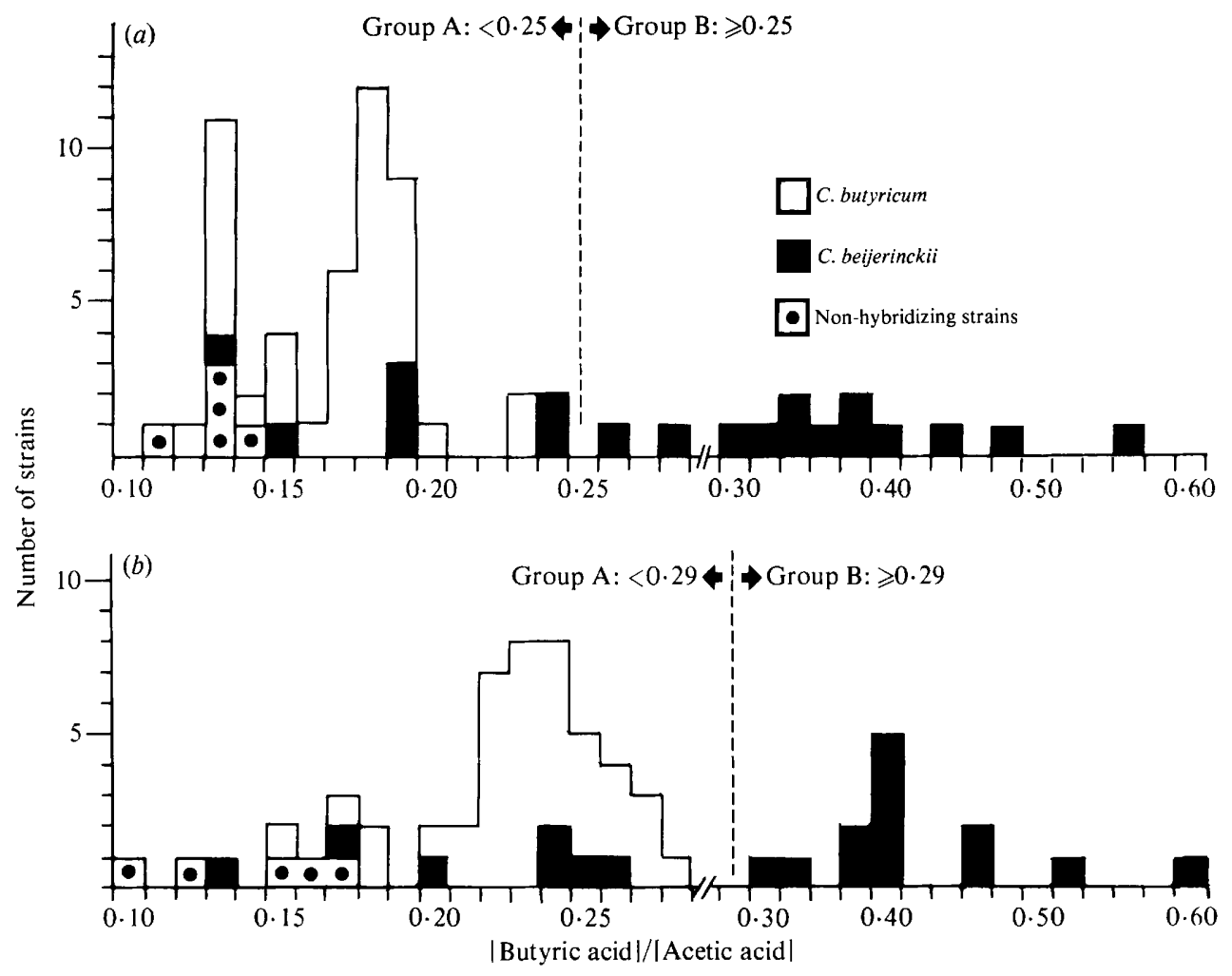

Fig. 3. Diagrammatic representation of the values of the butyric acid/acetic acid ratio (calculated from molar concentrations) measured after $3 \mathrm{~d}$ growth in (a) SIGA broth and (b) TYGA broth.

beijerinckii VPI 5481, which respectively fit in chromatography groups A and B, and with strain 1106 , belonging to DNA hybridization group III and to chromatography group A. The results are shown in Fig. 4. The butyric acid/acetic acid ratio of $C$. butyricum VPI 3266 varied from $0 \cdot 12$ to 0.14 in SIGA and from 0.21 to 0.24 in TYGA (Fig. 4a); variations for C. beijerinckii VPI 5481 were 0.35 to 0.43 in SIGA, and 0.49 to 0.60 in TYGA (Fig. $4 b$ ); strain 1106 showed variations ranging from 0.09 to 0.11 in SIGA, and from 0.11 to 0.13 in TYGA (Fig. $4 c$ ). These data represent a maximum variation of 6 to $10 \%$ from the mean value for each strain in each medium. On the other hand, several other strains were tested twice or three times (including all strains of CF group A3, see later). Similar results were obtained (data not shown). The most important feature is that no strain ever fitted into a chromatography group other than that reported for each strain in Table 1 and Fig. 3.

\section{Fermentation patterns}

The ability to ferment glycerol, inositol and ribose was determined for each strain following the strictly defined conditions described in Methods. The 65 strains showed the three different fermentation patterns listed in Table 3. These results, combined with those of GLC analysis, allow the definition of six 'chromatography-fermentation groups' (CF groups) obtained by the combination of the chromatography groups $A$ and $B$ with the fermentation patterns 1 to 3 . The CF group of each strain is given in Table 1. The distribution of the 65 strains in the CF groups is shown in Table 4.

\section{DISCUSSION}

The DNA hybridization experiments allowed the preliminary identification of the strains included in this study. The results are in complete agreement with those of Cummins \& Johnson 

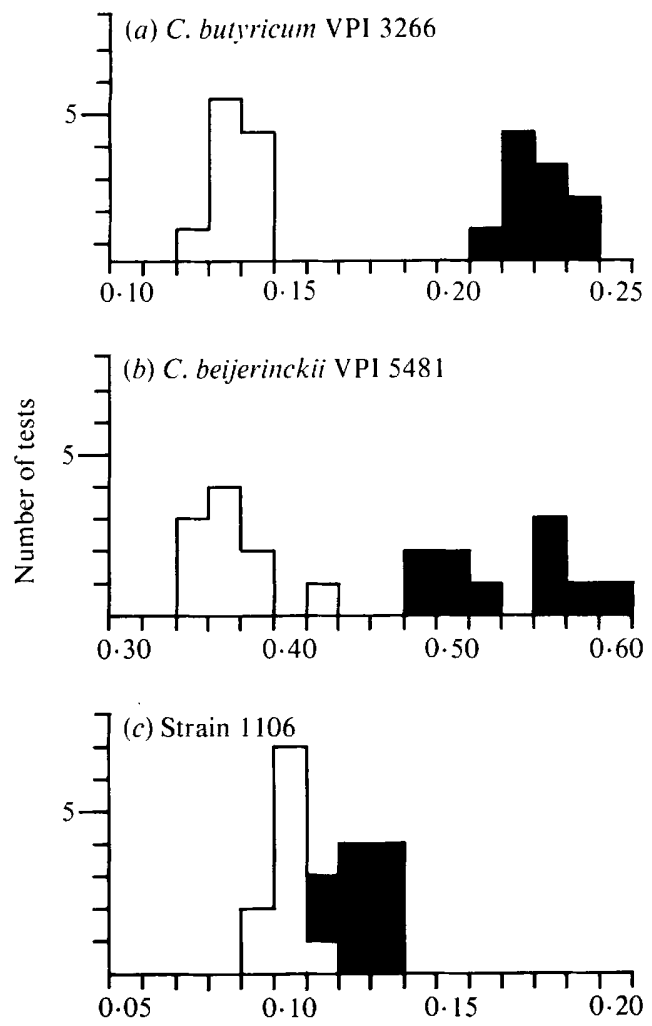

[Butyric acid]//Acetic acid]

Fig. 4. Reproducibility of the determination of the butyric acid/acetic acid molar ratio in SIGA broth $(\square)$ and TYGA broth ( $)$.

Table 3. Fermentation patterns

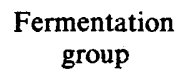

1

2

Fermentation of :

$\overbrace{\text { Inositol Ribose Glycerol }}$

+ , Production of acid under the conditions described in Methods; -, no production of acid.

Table 4. Distribution of the 65 strains in the CF groups

See text for definition of CF groups.

CF group

\section{Al}

A2

A3

B1

B2

B3

Total no. studied

$++$

$-$
No. of strains of:

\section{No. of strains of:}

C. butyricum C. beijerinckii Non-hybridizing strains


Table 5. Properties of strains belonging to $C F$ group $A 3$

\begin{tabular}{|c|c|c|c|c|}
\hline \multirow{2}{*}{ Strain } & & \multicolumn{2}{|c|}{ Butyric acid/acetic acid ratio* in } & \multirow[b]{2}{*}{ Gel type } \\
\hline & & SIGA & TYGA & \\
\hline \multirow{3}{*}{\multicolumn{2}{|c|}{$\begin{array}{l}\text { C. butyricum Meb } 125 \\
\text { C. beijerinckii CNRZ } 653 \\
\text { C. beijerinckii CNRZ } 530\end{array}$}} & $0 \cdot 17$ & $0 \cdot 15$ & $\alpha$ \\
\hline & & $0 \cdot 24$ & 0.26 & $\beta$ \\
\hline & & 0.24 & 0.24 & $\beta$ \\
\hline \multirow[t]{5}{*}{ Non-hybridizing strains: } & 1104 & $0 \cdot 13$ & $0 \cdot 12$ & $\gamma$ \\
\hline & 1106 & $0 \cdot 10$ & $0 \cdot 13$ & $\gamma$ \\
\hline & 103282 & $0 \cdot 11$ & $0 \cdot 16$ & $\gamma$ \\
\hline & 105082 & $0 \cdot 14$ & $0 \cdot 10$ & $\gamma$ \\
\hline & 105282 & $0 \cdot 13$ & $0 \cdot 17$ & $\gamma$ \\
\hline
\end{tabular}

(1971), who showed that clostridia of the butyricum group belong to two main species, $C$. butyricum and C. beijerinckii. Five strains in this study are not related to the reference strain of either of these two species, although they are phenotypically indistinguishable. Further studies are needed to determine whether they constitute a homogeneous hybridization group.

A new method of differential identification of $C$. butyricum and $C$. beijerinckii, based on quantitative GLC and the determination of fermentation patterns of glycerol, inositol and ribose, is presented in this paper. Two chromatography groups are defined by the determination of the butyric acid/acetic acid ratio after $3 \mathrm{~d}$ incubation in SIGA or TYGA. Of the $20 \mathrm{C}$. beijerinckii strains studied, 13 belong to chromatography group $\mathrm{B}$, which does not include any other strains (Fig. 3). Strains of the butyricum group showing a high butyric acid/acetic acid ratio can thus be identified with this test alone. Chromatography group $A$ is more heterogeneous, since it includes representatives of the three DNA homology groups (Fig. 3, Table 4), and the examination of sugar fermentation by strains of this group is necessary for their identification.

Clostridia of the butyricum group are highly saccharolytic, fermenting a great variety of carbohydrates. Fermentation of glycerol and mannitol has been used by several authors to distinguish between species (Breed et al., 1957; Beerens et al., 1962), but many strains cannot be identified by this technique (Cummins \& Johnson, 1971). Nevertheless, the fermentation patterns for glycerol, inositol and ribose are a useful test for the identification of strains of this group, when the test is done under strictly defined conditions. Three different fermentation patterns were obtained with the 65 strains studied (Table 3). The combination of chromatography groups with the fermentation patterns allowed the definition of six CF groups, $\mathrm{A} 1, \mathrm{~A} 2, \mathrm{~A} 3, \mathrm{~B} 1, \mathrm{~B} 2$ and $\mathrm{B} 3$. The CF grouping permits the classification of many strains of chromatography group A (Table 4), since strains of CF group A1 belong to C. butyricum, and strains of CF group A2 are all $C$. beijerinckii. However, CF group A3 includes phenotypically indistinguishable strains of all three hybridization groups, for which it is necessary to perform a DNA hybridization experiment or, more conveniently, to determine their protein PAGE pattern (Fig. 2) in order to make a precise identification. The eight strains of CF group A3 share all the phenotypic properties of clostridia of the butyricum group as defined in Methods. The 'non-hydridizing' strains have a very low butyric acid/acetic acid ratio, particularly in SIGA broth where they show the five lowest values of all strains tested (Fig. 3, Table 5). However, there are too few strains in CF group A3 to show whether this result is statistically significant.

Until now, no method of differential identification of $C$. butyricum and $C$. beijerinckii has been available for the routine diagnostic laboratory. A PAGE analysis of native cell proteins was recently described by Cato et al. (1982), but this method was poorly reproducible in our hands and results were very dependent on the growth medium employed. We also tried to perform rapid PAGE techniques of SDS-denatured proteins, as described, for example, by Moore et al. (1980), but a gel densitometer appears to be necessary for clear results. The main advantages of the more tedious techniques described in this paper are that differences between the four gel types are visible to the naked eye, and that the results are not dependent on the growth medium. 
Using the 'CF groups' method, 57 ( $88 \%$ ) of the 65 strains of the butyricum group included in this study can be easily and reliably identified with techniques that are currently used in the anaerobe diagnostic laboratory. Quantitative GLC analysis of fermentation products allows the identification of $C$. beijerinckii when the butyric acid/acetic acid ratio is high; if this ratio is low, determination of the fermentation patterns allows the identification of the other strains, except those belonging to CF group A3.

This work also showed that all our $\beta$-lactamase-producing strains of the butyricum group are 'true' C. butyricum, and that $C$. butyricum is mainly isolated from samples of human origin (Table 1). This raises the question of the potential pathogenicity of this organism (Popoff \& Sebald, 1981). The 20 strains of $C$. beijerinckii included in this study were obtained mainly from contaminated dairy products (Table 1), and we have never found any strain of this species from a human source.

The authors are very grateful to F. de Cadore, F. Craz and J. Hubert for the preliminary selection of some strains. We greatly thank M. Y. Popoff (Service des entérobactéries, Institut Pasteur) for his assistance in performing the DNA hybridization experiments and preparing the manuscript, and Professor M. Sebald for her constant support during the course of this work.

\section{REFERE N CES}

Beerens, H., Castel, M. M. \& Put, H. M. C. (1962) Caractères d'identification de quelques Clostridium du groupe butyricum. Annales de l'Institut Pasteur 103, 117-121.

Breed, R. S., Murray, E. D. G. \& SMith, N. R. (1957). Bergey's Manual of Determinative Bacterio$\log y, 7$ th edn. Baltimore: Williams \& Wilkins.

Brenner, D. J., Steigerwalt, A. G., Falcão, D. P., WeAver, R. E. \& FANNING, G. C. (1976). Characterization of Yersinia enterocolitica and Yersinia pseudotuberculosis by deoxyribonucleic acid hybridization and by biochemical reactions. International Journal of Systematic Bacteriology 26, 180-194.

Cato, E. P., Hash, D. E., Holdeman, L. V. \& Moore, W. E. C. (1982). Electrophoretic study of Clostridium species. Journal of Clinical Microbiology 15, 688-702.

Crosa, J. H., Brenner, D. J. \& Falkow, S. (1973). Use of a single-strand specific nuclease for analysis of bacterial and plasmid deoxyribonucleic acid homo- and heteroduplexes. Journal of Bacteriology 115, 904-911.

Cummins, C. S. \& Johnson, J. L. (1971). Taxonomy of the clostridia: wall composition and DNA homologies in Clostridium butyricum and other butyric acidproducing clostridia. Journal of General Microbiology 67, 33-46.

Grimont, P. A. D., Popoff, M. Y., Grimont, F, CoYnault, C. \& Lemelin, M. (1980), Reproducibility and correlation study of three deoxyribonucleic acid hybridization procedures. Current Microbiology 4, 325-330.

LAEMMLI, U. K. (1970). Cleavage of structural proteins during the assembly of the head of bacteriophage T4. Nature, London 227, 680-685.

MAGOT, M. (1981a). Résistance aux pénicillines dûe à la production d'une bêta-lactamase chez les Clostridium du groupe butyricum. Comptes rendus hebdoma- daires des séances de l'Académie des Sciences, série III 292, 285-287.

MAGOT, M. $(1981 b)$. Some properties of the Clostridium butyricum group $\beta$-lactamase. Journal of General Microbiology 127, 113-119.

Moore, W. E. C., Hash, D. E., Holdeman, L. V. \& Cato, E. P. (1980). Polyacrylamide slab gel electrophoresis of soluble proteins for studies of bacterial floras. Applied and Environmental Microbiology 39, 900-907.

PopofF, M. R. \& SEBald, M. (1981). Mise en évidence chez Clostridium butyricum d'un facteur thermostable responsable du pouvoir pathogène expérimental. Comptes rendus hebdomadaires des séances de l'Académie des Sciences, série III 292, 763-766.

PopofF, M. Y. \& CoYNAUlT, C. (1980). Use of DEAEcellulose filters in the $S 1$ nuclease method for bacterial deoxyribonucleic acid hybridization. $A n$ nales de Microbiologie 131A, 151-155.

Rousseau, M., Hermier, J. \& Bergere, J. L. (1971). Structure de certains Clostridium du groupe butyrique. I. Sporulation de Clostridium butyricum et Clostridium saccharobutyricum. Annales de l'Institut Pasteur 120, 23-32.

Sebald, M. \& Brefort, G. (1977). Recherche et identification des anaérobies en bactériologie courante. Revue du Praticien 27, 107-118.

Sebald, M. \& Costilow, R. N. (1975). Minimal auxotrophic requirements for Clostridium perfringens and isolation of auxotrophic mutants. Applied Microbiology 29, 1-6.

Schink, B., WARD, J. C. \& ZeIkUS, J. G. (1981). Microbiology of wetwood: importance of pectin degradation and Clostridium species in living trees. Applied and Environmental Microbiology 42, 526-532.

WeSTPHAL, O. \& JANN, K. (1965). Bacterial lipopolysaccharides. Methods in Carbohydrate Chemistry 5 , 83-92. 